\title{
POST-NEO-ROMANTICISM AS A PHENOMENON OF THE CONTEMPORARY CULTURE
}

\section{Olena Kolesnyk}

\section{INTRODUCTION}

The term "Romanticism" is traditionally used in two meanings. Firstly, it is the title of a cultural style, which existed in the late 18 - early 19 century. In the wider sense, Romanticism it is a trans-historical cultural phenomenon, opposing the materialistic approach to life and naturalistic artistic representation. According to N. Berdyaev, it is characteristic only for Western culture, though some parallels could be found in other cultural traditions. Sometimes it is stated that in the history of culture realistic and romantic creative methods alternate. Indeed, in European culture we can discern some rhythmic fluctuations between the cardinally different principles which F. Nietzsche's termed "Apollonian" and "Dionysian". In terms of K. G. Jung's Analytic Psychology, Romanticism can be viewed as a manifestation of a visionary artistic creativity (as opposed to the rational method of "writerpsychologist"). The Romantics themselves often compared spontaneity and irrationality of creativity to the working of Nature or some super-Natural forces. In this context, the personality (microcosm) and the universe (macrocosm) are of more importance to the author than society, though the latter also has its symbolic potential.

It is customary to begin the history of romanticism (in both senses of the word) from the eighteenth century, distinguishing Pre-Romanticism, High Romanticism, and Neo-Romanticism. However, "diffuse" forms of romanticism existed both before and after its "official" time limits.

In the English-speaking tradition, Neo-Romanticism has no "upper limit" - it does not disappear, but gradually dissolves in other cultural areas of the 20 century. In the contemporary Ukrainian humanities, the existence of Neo-Romantic forms in the current culture has scientific recognition. However, this phenomenon is much more important and more diverse than just some marginal trends described separately. The Neo-Romantic tendencies of the late 20 - beginning of 21 century are reaching such a level of selforganization on a global scale, which allows us to speak no longer about individual manifestations of romantic moods, but about the cultural phenomenon of a higher order. In scale and characterit is comparable with the Neo-Romanticism of the late 19 - early 20 century, and therefore deserves a separate name. We suggest it to be "Post-Neo-Romanticism". 


\section{The sources and characteristics of the Post-Neo-Romanticism}

Some elements of Romantic world outlook can be traced at least to Hellenistic and Roman art. I. Ratsky suggested the term "romantic genres" roughly equivalent of the English term "romance" (in the wider sense of word). According to this researcher, it is a complex conglomerate of genres, to which both the Hellenistic novel, various forms of Medieval literature, and Shakespeare's last plays belong ${ }^{1}$. In the contemporary Ukrainian humanities, there are instances of usage of the term "romence". Furter use of the concept is highly recommended as it implies the continuous, trans-historical tradition that connects the early (Hellenistic and Medieval) adventure stories with the Romanticism of the 18-19 century, and further with the contemporary fantasy, some sub-genres of which clearly show the same archetypal pattern as the ancient texts. The same can be said about some works of science fiction ("Star Wars" for example).

The proto-Romantic features of the Hellenistic novel include outstanding characters, shocking tribulations and exotic countries. Even in some texts that can seem anti-Romantic, we can find features, that much later would become crucial for the truly Romantic genres. For instance, in the Roman literature we see for the first time the focus on the life of a metropolis as a socially, culturally and religiously heterogeneous environment, which contributes to the marginality and anonymity of characters and to the dramatic rises and falls of their fortune. The most vivid example is Petronius' "Satyricon". There city becomes the integral part of the story and the only possible background for the events. Considering the contrast between the social position of the author the "arbiter of refinement" at Emperor Nero's court - and the "urban jungle" he depicts, we can see "Satyricon" as one of the first examples of slumming, typical of Neo-Romanticism. This kind of anti-glamor is being revived in our own time. In this context we can also mention the Baroque Picaresque novel, where a big city is depicted as a mysterious and dangerous environment with its complicated, multi-faceted life. It should be especially noted that the low and commonplace (namely, the life of lumpens and criminals) could be seen as exotic and even alluring.

During the Middle Ages, due to the civilizational changes, the city in the literature recedes into the background. Romances (in the proper sense of the word) return to the natural setting. Here we see the contrast between "the fortress" and "the forest/field". The same sharply drawn opposition between "culture" and "nature" structures the world of Shakespeare's "King Lear" that gives the summary of the generalized epic times of European

\footnotetext{
${ }^{1}$ Ratsky, I. (1977) The last Plays of Shakespeare and the Tradition of the Romantic Genres in Literature. Shakespearean Readings 1976. P. 104.
} 
history. The theme of nature as a source of both danger and spiritual rebirth would become very important for the High Romanticism. Later it would reappear in some variants of the adventure genre and fantasy.

Traditional elements, including the inherited Classical topoi and the autochthonic folklore motifs, re-interpreted in the light of new, antiEnlightenment sentiments, lead to the formation of what is now known as PreRomanticism. At the center of the world picture was placed not reason but passion. In our context, there are two phenomena that deserve special attention: 1) the emergence of the Gothic novel, which still has a paradigmatic significance for several genres, and 2) the emergence of Ossianism. The latter greatly influenced not only literature, but also political culture of Europe of the 18-19 centuries, and became a factor in a series of national revivals that have changed the map of Europe and the world.

The rise of the High Romanticism with its new world model meant the emergence of new genres. The notable achievements of High Romanticism were the creation of the historical genre (W. Scott and V. Hugo) and the appeal to folklore (the Grimm brothers, H. Ch. Andersen and others). For the first time, history was seen as a way of finding the origins of one's own culture. This "search for roots" was of particular importance to peoples "without history" and to peoples whose state traditions for some reason had been broken. For example, in Ukraine, where the national culture was declared non-existent by the Tsarist government, there were works that restored historical memory. It is in this context that one can consider the works of I. Kotlyarevsky and T. Shevchenko, and some works of M. Gogol.

It is usually stated that the second half of the 19 century was the time of predominance of realistic, even naturalistic literature, which has eclipsed the Romantic art, which was only revived in at the turn of the century as the Neo-Romanticism. However, the watershed between High Romanticism and Neo-Romanticism of the late 19 - early 20 centuries is not quite clear, since throughout the nineteenth century realism as a principle coexisted with romanticism. Here are some important trends:

1. In some countries - including Ukraine - romantic tendencies existed throughout the 19 century and moved to the 20 century.

2. Works of romantic nature ("Moby Dick", "The Song of Hiawatha", "The Legend of Uhlenshpigel", etc.) continued to appear in the second half of 19 century; the correlations between them and the irrationalistic philosophy deserves separate study.

3. Many notable works of art, predominantly realistic, had noticeable traits of Romanticism. Quite a typical phenomenon was the "physiological essay", where the city was regarded as an integral organism and described at the same time "scientifically" and poetically. Probably the pinnacle of such a 
description of the inner life of city, related to the inner life of human soul, is found in the novels of Ch. Dickens and F. Dostoevsky.

4. During this period the ideas of High Romanticism diffused in the culture, gave rise to the new genres, such as adventure novel and its variants, primarily detective, thriller, science fiction and fantasy.

This cultural complex can be termed an "intermediate" Romanticism of the mid to late 19 century.

Adventure literature is a genre conglomerate that includes such different forms as a chivalry romance and science fiction. Most of these genres - social adventure, historical adventure, geographic adventure, detective, fantasy etc have formed since the middle of the nineteenth century. The works of these genres often were popular and commercially successful. Some of them since then have acquired the status of classics.

The formation of the Neo-Romanticism proper took place in the 1880-s. Its British version represented by R. L. Stevenson, H. R. Haggard, A. Conan Doyle, R. Kipling, defined the canons of the classic adventure novel, solidifying the emergent genres. One of the characteristic traits of NeoRomanticism was the ordinary, down-to-life protagonist, radically different from the "superhero" of the High Romanticism. It helped the audience to identify with the hero, and also to see the real life as wonderful and mysterious. In an extreme situations a Neo-romantic character found will and strength to win. Such stories, despite the exceptional nature of the events described in them, had close correlations in real life. Let us remember, that it was the age of the last great geographical discoveries, which the entire world followed with admiration.

Neo-romantic texts often hide behind the seeming simplicity a serious and complex content, open to a variety of interpretations. For instance, dozens of adaptations of R. L. Stevenson's "Treasure Island" or A. Conan Doyle's "The Hound of the Baskervilles" have not exhausted the multi-layered philosophical issues of the literary sources. On the example of Stevenson's works, one can study a curiously actual phenomenon of fear of inner chaos, symbolized by the famous split of a person into two personae: Jekyll and Hyde. This theme is closely connected to: 1) the universal archetype of Shadow; 2) the British folk tradition of two worlds; 3) the Victorian Novel of mysteries; and 4) the popular ideas about the complex structure of the psyche, which led to the almost simultaneous discovery of the subconscious by S. Freud and I. Franko.

The theme of the hidden secret side of the world underlies the structure of the classic detective. It is characteristic that A. Conan Doyle not only created the iconic image of a detective and a paradigmatic story model, but also initiated a kind of urban epic that mythologizes London (and can be 
transferred to any city). Detective and thriller (which were not very different at first and still have intermediate forms) tend to portray the modern city not only as a place of action, but also as an active medium, and even as a fullfledged hero of the story. Some cities have special charisma. One of them is London, which is not surprising, given its status as the centre of a world empire that it had at the time of the genre's inception. Other cities may be brought to the foreground by their particular geopolitical position, such as Istanbul, which became the scene of thrillers from such excellent writers as J. Buchan, T. Hayes, D. Brown, E. Kostova and O. Pamuk.

G. K. Chesterton became a theoretician and apologist for the detective genre, whose pathos is the exact opposite of the pathos of J. Ortega y Gasset. He regarded detective story as a form of myth that reveals the magical reverse of everyday life ${ }^{2}$. The enchanted world of a chivalry romance is, oddly enough, compatible with the image of the modern metropolis. A fight with a criminal can turn into a spiritual quest and a triumph over sin.

One more important genre, emerging at the second half of 19 century, was literary animalistics. It was one of the first attempts to look at the world from a fundamentally different perspective. One of its derivates is the now-popular xenofiction, which examines the non-human lifeworld. Finally, during this very period, the canon of the literary fairy-tale is emerging. It became a starting point for the fantasy genre, as well as for the European version of magical realism.

The Continental counterpart of the mostly British and American NeoRomanticism is the Symbolism. Despite all the dissimilarity of the philosophical lyrics and the adventure novel, their basis is common: a sense of the end of an era and the search for a way out of the crisis of everyday life. If British Neo-Romantics preached the courageous willingness to take on any challenge, then the Symbolists were inclined to seek salvation from the prose of life in the transcendental. It could be religion, or the perfect world of the ethnic past. As in the period of High Romanticism, this latter variant was especially relevant for nations that had to claim their identity. The Ukrainian version of Neo-Romanticism is represented by the work of Lesya Ukrainka (who used the term "new romanticism"), and by the early poems of P. Tychyna and the Neoclassics.

In the Soviet and post-Soviet critical traditions it is commonly stated that Neo-romanticism went into decline in the 1910-s. In the English-speaking tradition, Neo-romanticism has no upper limit: it includes all works that oppose naturalism on the one hand and avant-gardism on the other. Given the

${ }^{2}$ Chesterton, G. K. (2020, January 07). A Defence of Detective Stories. Retrieved from https//www.chesterton.org/a-defence-of-detective-stories/ 
historical context, the upper limit of the "classical" Neo-Romanticism is 1914. The collapse of empires, the revolution in Russia, the terrible losses on the fronts, the general mood of despair and disappointment could not but lead to radical changes in the way of life and type of culture. Therefore, although after the First World War there were still some texts, clearly Neo-romantic in the spirit (such as thrillers of J. Buchan), the literature of a completely different nature came to the fore.

After the First World War, romanticism did not disappear, but transformed. In 20 century Romantic tendencies were quite strong but diffuse, and thus seldom viewed as a whole phenomenon. Depending on the predominant ideology and the personal inclinations of the author, Romantic sentiments could lead both to the revolutionary urge, or to the complete escapism. Because of such great ideological and stylistical diversity, it is difficult to give it a specific name and definition, so let us call it "the 20 century romantic trends". Taken together, they occupy a significant place in the culture, but do not form a particular school with clear agenda or stylistic unity. This heterogeneous complex of texts is united by their rejection of the commonplace. In the period between the world wars, appeared significant texts without direct genre analogues ("Master and Margarita" by M. Bulgakov), or texts that have laid the foundations of a genre that would develop only in a few decades ("The Hobbit" by J. R. R.Tolkien). However, on the whole, romanticism does not dominate.

The new revival of the romantic tendencies started after the Second World War, in the period of reflection on the losses and the search for a way out of spiritual paralysis. This function was originally performed by the genre of fantasy and philosophical fairy tale before its transformation into a form of escapism. Another fantasy variant, continuing the tradition of Kipling's "Puck of Pook's Hill" aims at reconstructing the ancestral and national heritage at the micro-historical level.

Romantic tendencies played significant role in the Soviet culture; it is known that the term "revolutionary romanticism" was proposed as an alternative to "socialist realism". The romantic in the USSR took form of striving for revolutionary, labour and creative achievements. Unlike most romantic traditions, here the personality does not oppose the community and the state. On the contrary, the extraordinary and mysterious forms an attractive shell of the socially useful. However, even within such a strict canon, there were extraordinary works. In addition, there were some texts and even whole trends going beyond the limits of the Socialist Realism, such as in Ukrainian "chimerical novel" (O. Ilchenko etc.).

The classic Neo-Romantic literature retained its popularity throughout 20 century. These books still have enormous international audience, and 
moreover, they are constantly re-interpreted both in screen adaptations and in the new works of art that use their imagery and structure. This widespread and multifaceted process is rapidly turning into a phenomenon of contemporary art, which can be defined as the "Post-Neo-Romanticism". This term, if somewhat unwieldy, refers to its connection with the Neo-Romanticism (rather than the High Romanticism), and its liberal use of the Post-modern devices. For example, the Neo-Romantic texts can be modernized, combined, or interpreted in terms of retro-futurism, that give rise to Steampunk and suchlike forms. The new trend can be traced to the times of the collapse of the Soviet Union and the consequent structural changes of the global culture. Now it is becoming a noticeable factor of the current cultural life in the postSoviet space, Europe, North America and the Far East.

The most notable feature of the Post-Neo-Romanticism is the replication of the Neo-Romantic pattern: a person gets into an extreme situation that requires him/her to reach the full potential. The overall tone becomes somewhat gloomier than in the 19 century, as both authors and readers know full well the horrors of the outer and inner worlds. Recognizing Hyde's presence in each person leads to the replacement of hero with an antihero. However, these tendencies are not purely negative, since the main message of the text may be in finding true values and new ways of person's integration into society.

Another feature of the trend is hyperbolization, which sometimes reaches the limit of parody and self-parody. The contemporary recipient is not easy to impress. Therefore, authors use the whole arsenal of means of emotional influence.

If Neo-Romanticism created genre canons, then its contemporary version tends to inter-genre synthesis. In particular, fantasy elements are widely introduced into the mainstream literature. Another trend is experimenting with the content and form of works. In Post-Neo-Romanticism, a set of Postmodern guidelines and techniques - polyphony, nonlinearity and deconstruction of the text, widespread use of quotations and allusions - is involved in modelling works based on Neo-Romantic literature. Very often contemporary writers directly refer to the iconic works of British Neo-Romanticism, using Postmodernist approach.

Generally, the contemporary interpretation of the Neo-Romantic texts may aim at:

- adequate reproduction (adaptation, illustration, creation of comic books based on books, etc.);

- modernization ("Sherlock" series, where the action takes place in the 21 century);

- concentration of characters of several works in one intertext ("The League of the Extraordinary Gentlemen" comics and film); 
- creation of historical fantasy, steampunk, crypto-, alternative- and pseudo-historical works based on their motives;

- use of typical Neo-Romantical plot elements or even a whole story, transferred to our own times (for example, N. Gaiman's "Neverwhere" repeats the structure of "The Lost World" by A. Conan Doyle).

One of the typical traits of the best examples of the Post-Neo-Romantic literature is the interest to the hierophany of the secret meaning of everyday life. A rebellion against the rationalization of the magical we see in T. Burton's "Sleepy Hollow" and T. Gilliam's "Brothers Grimm", which completely reimagine their literary primary sources. In S. Clarke's "Jonathan Strange and Mr. Norrell" the dangerous but vital element of magic (and its correlates: folk, female, subconscious, etc.) interferes with an overly-orderly life. Historical genres are increasingly being replaced by various "pseudo-historical" variants, in particular in the form of time-punk and other variants of "alternative".

The interest in the second half of the 19 century is growing. Even in genrepure fantasy, there is a noticeable departure from the "Tolkien" to the "gaslight" entourage. Such forms are most characteristic of British literature, however, elements of steampunk are noticeable in other countries as well; some motives are seen in Ukrainian literature (L. Luzina).

The Victorian era (and its counterparts in other countries) is depicted as ambivalent. The critique of disempowerment, gender inequality, colonialism, environmental problems, spiritual crisis, and dehumanization are combined with palpable nostalgia. The axiological accents of particular works depend largely on the author and the target audience (male or female, adult or teenage).

Post-Neo-Romanticism is characterized by a kind of anti-glamor. For example, the poetics of steampunk implies the dirt, smog and rust of a big city. However, it is not about democracy or the revisionist "truth of life". Poetization of poor suburbs, landfills and sewers cannot be called a new phenomenon (remember the 19 century concept of slumming), but in modern art it reaches its limits.

One of its most shocking manifestations is necro-esthetics, noticeable in both elitist and popular culture (glamorous vampires, variations on the Frankenstein monster, completely non-folk zombies, etc.). It is a complex phenomenon, but one of its aspects is the mythologization of the rejected. The idea of mysterious independent life of inanimate objects leads to the possibility of perceiving the dump as a "concentrate of spirit" - as in the scenery of the famous musical "Cats". The dump and the museum are interchangeable: the museum can be seen as a collection of "magnificent, rare, strange and expensive junk", and the dump - as a source of ideas and

\footnotetext{
${ }^{3}$ Gaiman, N. (2005) Neverwhere. London, Great Britain: Headline. P. 173.
} 
materials for museum installations. The lives of declassified elements, the non-life of dead bodies, and the existence of non-animated objects all can be comparable in their marginality. The ghetto, the madhouse, the shelter, the cemetery, the landfill are all in one semantic row.

N. Gaiman in "Neverwhere" created the complete myth of this shadow world. The storyline of the novel turns inside out a stereotypical Hollywood plot. Instead of a looser who has been initiated and returns home with new strengths and perspectives, we see a person who escapes from his own success back to the "hyper-slums" - the only place where he can find real life and real feelings.

In general, Post-Neo-Romanticism is critical towards political, economic and social realities. However, the rebellious image can be easily commercialized. As in the times of High Romanticism, a wind-blown cloak and dishevelled hair have become fashionable attributes, so now imitation of rags can be part of a rather expensive image.

In any case, the new trend is actively transcending the art, often determining the self-identification of his adherent, which manifests itself in real-life image and behaviour. This is evident from such phenomena as: varieties of the Gothic subculture, Tolkienism, role-playing games, historical reconstructions, etc. In spite of theoretical differences, some of these trends can easily combine, creating an alternative reality of life.

\section{Guy Ritchie's "Sherlock Holmes" dylogy as a quintessence of Post-Neo-Romanticism}

G. Ritchie's "Sherlock Holmes" films (as well as the "Sherlock" series, which appeared almost simultaneously), radically differ from all previous adaptations of A. Conan Doyle's stories.

One of the most noticeable tendencies of the contemporary culture is the fluidity of the borders between the art and science, the image and the theory. Sometimes the artists are the first to notice, or at least, to draw attention to some serious problem. In that way, Guy Ritchie's film "Sherlock Holmes" (2009) and its sequel "Sherlock Holmes: A Game of Shadows" (2011) have a diagnostic quality, as they not only present the in-depth analysis of the late XIX - early $\mathrm{XX}$ ct., but also warn the recipient about the dangers of the contemporary politics.

Sherlock Holmes is one of the eternal characters, which have acquired a kind of independence from their authors and transcended the limits of time and space. Still, his personality is quite definite, and the totality of Arthur Conan Doyle's detective stories has been defined as "the Canon". That is why all the numerous artistic interpretations of the character and the story (screen adaptations, literary sequels etc.) can be roughly divided into two types:

1. The interpreter aims at achieving the maximal "correctness", trying to make every detail historically accurate and true to the literary source; 
2. The interpreter sees Conan Doyle's stories only as the starting-point for their own imagination.

It is clear, that interpretations of the second type can be quite distant form the original. However, choosing the first strategy also does not guarantee the congeniality of the new work of art and the classical stories. The main cause of the discrepancy is the absence of the surprise element for the recipient. For their first readers, Conan Doyle's stories were vibrantly relevant in their problematics, thrilling in their suspense and unpredictability. Now this thrill is considerably dulled, because it is hard to find an adult person, who does not know the final of most stories. Therefore, the screenwriters try to go away from the original stories with their predictable finals and explore the unknown.

Guy Ritchie's two films are somewhere in between the two abovementioned types. The stories were completely rewritten. Nevertheless, the depiction of Sherlock Holmes's world, the general atmosphere, the stylistics and the rhythm are remarkably true to the original. The author made the instauration of the character and plot, clearing away the accumulation of the stereotypes but retaining the "hard core" of the Canon.

The screenwriter's task was to write a new story, greatly upscaling the events but maximally using all the original Conan Doyle's material. Just one example. Since the times of Chekhov, we know that a rifle hanging on the wall, must fire eventually. For Conan Doyle, the Detective's smoking-pipe could be just an accessory. In the contemporary art, every object must work, and the pipe works hard, turning into a tool for bomb defusing, an instrument of fire diversion in the auction hall etc. In that way the writer and the director take what is already present in the original stories and "blow it up".

It is interesting - even symptomatic - that at the same time a different team used much the same principles when creating "Sherlock" series. In both films, we see explication of subtexts, heightening the emotional score, visualization of the individual process of thinking and different mind games etc. Very noticeable are the protagonist's incomprehensible actions that demand the leap of faith from other characters as well as from the recipient. The contemporary setting of "Sherlock" not only heightened the spectators' emotional engagement, but also created the effect of the "stereoscopic vision" of history. Sometimes we can see how much the world changed. And on the contrary, some problems remain: almost 150 years later Watson again returns from Afghanistan.

Still, the implicit philosophical basis of Ritchie's films is even more complex.

It is evident, that the contemporary filmgoer is used to the maximal scale of the conflict and its impact. Such an attitude is quite different from the 
paradigm of the classical crime story, where the focal point is the complicated riddle that must be ingeniously solved. It does not mean that the detective is indifferent to the ethical and social problems. G. K. Chesterton was one of the first to state that one of the main functions of the classical detective was to demonstrate the triumph of justice, and thus - triumph of Cosmos of the destructive forces of Chaos. Much later, K. Summerscale concluded, that detective story takes reader into the mystery of death and rebirth ${ }^{4}$. Taking into consideration the experience of the XX ct., D. Kluger showed the transformations of the detective genre, sometimes leading to the triumph of Chaos $^{5}$. However, G. Ritchie chose to retain the traditional, much more optimistic, approach.

Strictly speaking, the structure of both Ritchie's "Sherlock Holmes" films is much closer to thriller, than to the classical detective. Detective's main point is in solving the already committed crime, in other words, in uncovering the secret of the past. Thriller in the modern sense of the term has appeared in the early 20 century, though its elements can be seen in earlier works, significantly, in Conan Doyle's "The Hound of the Baskervilles". While detective deals with the question "how it was done?" thriller - with "what will happen?" Often the protagonist is a more or less innocent bystander, caught in the stream of events and bound to fight for his life. Besides the duel with the forces of evil, the protagonist is often on the wrong side of the law, which complicates the game. Such a situation where a gentlemen's reputation was smirched, even temporarily, was not typical for the Victorian literature. However, since J. Buchan's "The Thirty-nine Steps" the plot where the hero evades both criminals and the police has become a staple.

In the second half of the 20 century, appeared a new sub-genre of thriller, where a brilliant and devious criminal forces a defender of the law to accept a kind of chess game. Mostly, such a game is initiated by a maniac. Ritchie's plot is more interesting, because both players are quite sane, though highly unusual personalities. In "A Game of Shadows" Ritchie turns this agon into the leitmotif of the whole story. In both films, we see the intellectual duel of almost equal participants, which creates powerful suspense.

It is clear, that in both stories Sherlock Holmes is defending the Cosmos and the principle of order and justice (though not necessarily the law). It seems only natural that his enemy must represent Chaos. But it is true only in the second film "Sherlock Holmes: A Game of Shadows", where appears the

${ }^{4}$ Summerscale, K. (2008) The Suspicions of Mr. Whicher, or The Murder at Road Hill House. London, Great Britain: Bloomsbury.

${ }^{5}$ Kluger, D. (2005). The Baskerville Mystery: The History of the Classical Detective. Moscow: Text [in Russian]. 
notorious Professor Moriarty. The villain of the first film is quite different. He also "plays for" Cosmos, only his version of the world order is a wrong one.

It is difficult to say whether the author planned his two films as the development of the same historiosophic theme. But we see clear and complete depiction of two different "crime paradigms": "classical" and "non-classical", or the totalitarian and the anarchic.

In the first film, "Sherlock Holmes", the hero's archenemy is the Lord Blackwood, rich and privileged, though - significantly - illegitimate. He combines his wealth, social standing and intellectual resource to seize the power in the country.

Here we can find many features, typical for the second half of the XIX ct., which combined the ancient tradition with the search for the new ways of thinking and acting. The antagonist is a representative of the ancient elite, who believes in his hereditary right to rule. At the same time, he wants to twist the already existing ancient institutions - from with the Masonic-like lodge to the Parliament - to suit his purposes. It is typical, that he searches to "marry" the occult lore with the latest scientific achievements. Such things were attempted in these times, and much later. One of the notable examples is Hitler's Ahnenerbe, a mysterious institution that collected and studied all the kinds of ancient lore for possible practical use. Some studies that try to establish the correlation between myth and science take place in our own time.

Guy Ritchie does not show these arcane experiments to be effective. Mostly, they serve to create the atmosphere of awe. Fear becomes a force in itself, helping to demoralize the opponents and oppress their minds. In such an atmosphere coup d'états becomes a possibility. Blackwood does not mean to destroy the state - he wants to seize it and change it according to his plans. No doubt, he would have turned it into an extremely right-wing hierarchical totalitarian world-state embracing both Britain and Northern America.

Blackwood's Dracula-like image, his quasi-religious terminology, his usage of some very antique occult tradition have an archaic feel. In a way, he is a throwback. But that is not all. Both his scientific achievements and his ability to manipulate the public opinion are shown to be effective.

A plot to seize the power in a state is not typical for the 19 century fiction. The existing order seemed too strong to think of that. Only the XX ct. with its experience of revolutions, world wars, coups and dictatorships, brought into the focus of attention stories about the charismatic leaders turning tyrants. John Buchan was one of the first to notice this tendency of "domination of spirit upon spirit"6, whether openly leading the masses, or covertly

\footnotetext{
${ }^{6}$ Buchan, J. (2010) The Three Hostages. The Complete Richard Hannay Stories. London, Great Britain: Wordsworth Classics. P. 678.
} 
manipulating them. In that way, when we recollect Lenin and Hitler's unpredictable rise to incredible power, the plot of the film goes far beyond the 19 century.

The second film, "Sherlock Holmes: A Game of Shadows", presents quite a different paradigm, even a different age. If Blackwood only experimented with the new technologies, there we see the coming of the mass production. Unfortunately, it is the mass production of the instruments of the mass murder. Moreover, there is a hint that this mass-production can be used to standardize human beings. Plastic surgery, "making" twins is just one example.

Professor Moriarty is not the embodiment of Chaos - after all, he is a mathematician and music-lover, which refers us to the Pythagorean notion of the cosmic harmony. Still, he does the work of Chaos, because his course is pure destruction without a hint of any new order.

Everybody knows that Professor Moriarty is the arch-villain of "Sherlock Holmes" stories. But he never appears in the spotlight. In the book, Watson does not see him at all, and knows only Holmes' brief description of his enemy's character and activity. Paradoxally, we do not even know Moriarty's name. It is supposed to be James, but actually, it is the name of Professor's brother. In a story, such a veil of mystery is good, but in the screen adaptation, "the Napoleon of Crime" must have a real and impressive presence and convincing psychological motifs.

Guy Ritchie brilliantly explained his character's peculiar combination of order and disorder. It is all in the title of Moriarty's monograph about the deviations of asteroids. This theme wakes in mind the discussion of Classical Greek and Roman philosophers, dealing with the trajectories of atoms, whether strictly deterministic (Democritus) or having a degree of freedom (Lucretius). However, for Moriarty this deceptive "freedom" becomes the source of catastrophes that from time to time burst the order of Cosmos. It is a convenient creed for him, for it combines the belief in the mathematically precise mechanism of the Universe, and the inevitability of periodical cataclysms in the work of this mechanism. If these cataclysms are natural and inevitable, it seems no great crime to produce one. Moreover, in such cosmic incidents, the collateral damage is inevitable and of no importance. This peculiar combination of fatalism and freedom of will is sufficient to justify any crime.

It is remarkable, that the story begins with the anarchist bombers, which is strictly in keeping with the historical truth. The turn of the centuries was the time of many ideologies, some of which become violent. However, later we see that these terrorist attacks were orchestrated by a person with no ideology at all. $\mathrm{He}$ is the tertius gaudens, who provokes the revolutionaries and the 
states to receive maximum gain. He cares about no one, and he does not belong to a certain country. That is why all the states can ruin themselves as long as he has a neutral enclave to enjoy his gains. It is quite close to the alleged position of the contemporary "international elite", whose worldwide mobility means that they are free to exploit and leave any country, having no loyalty to any people or any state. This new elite is not the aristocracy of old. They have no "origin", no lineage, and no motherland - just personal abilities that allow making money.

Such actions provoke different kinds of conflicts, which can turn into a full-scale war. We all have grown with the knowledge that the world wars are quite real. However, in the 19 century such a thing appeared quite unthinkable. That is why Holmes, who has no illusions about Moriarty's intentions, is ahead of his time. It is clearly seen in his usage of the formula "the fate of the Western civilization". The civilizational approach in his time was marginal; it was much later that Spengler's "Der Untergang des Abendlandes" popularized the conception. The term "Western civilization" is younger still. Thus, Guy Ritchie hints to the spectator that Holmes uses the contemporary historiosophic categories. He can see the future.

In the first film, the action is confined to London. In the second, significantly using not only train and steamer, but also the latest invention automobile - the heroes go abroad and see different countries in their interaction. Every state is characterized by its most prominent features. For example for France, it is revolutionaries, good wine, international summits, the unfinished Eiffel tower and the Opera. For Germany, it is a military factory.

Britain, France, Germany would become active participants in the forthcoming two world wars; Switzerland in both cases would manage to stay neutral. All this is foreshadowed in the plot, and the spectator has a kind of sad knowledge of the inevitable future events. For example, for the 19 century Britons Switzerland was beautiful and exotic but rather unimportant. In the 20 century, it became a symbol of neutrality, with all its positive and negative connotations. Combining these senses, Guy Ritchie gives the fatal Reichenbach Falls the completely new semantics.

Another theme seen in "A Game of Shadows" is the borders between the states, and the way to transcend these borders - both geographical and mental. In this way, mobile gypsies are of more help to the "concerned citizens" trying to prevent the collapse of the civilization, than their own bigoted governments. On the other hand, the crime lords are also no longer confined to one state. War and terrorism also become global. Unfortunately, this is all too true now. 
Guy Ritchie shows two seemingly diametrally opposing but equally unacceptable ways of behaviour. When openly practiced, they a qualified as criminal, but in their more covert form, they have a place on the margin of political forces.

The first of them is right-wing, based on the strict hierarchy and rigid order, that establishes the dictatorial world-state, based on deception and fear. The second one is anarchic, or, at least, using the revolutionary rhetoric for its own aims. The provocations, that may lead to the world war, are used to enrich a certain person who stays in a neutral country. The difference between their principles can be summarized as follows:

\begin{tabular}{|l|l|}
\hline \multicolumn{1}{|c|}{ Sherlock Holmes } & \multicolumn{1}{c|}{$\begin{array}{c}\text { Sherlock Holmes: } \\
\text { A Game of Shadows }\end{array}$} \\
\hline Cosmos in a twisted form & Chaos \\
\hline Traditions of state & Destruction of all traditional order \\
\hline Open power, hierarchy & Hidden control \\
\hline Giving orders & Making provocations \\
\hline Totalitarianism & Anarchy \\
\hline
\end{tabular}

Unfortunately, both these tendencies - extreme fundamentalism and selfcentered anarchism - in ideology and politics are still with us. Guy Ritchie's films visualize the twin dangers that must be avoided, heightening the recipients' awareness of the world problems.

\section{CONCLUSIONS}

Romanticism as a general cultural trend has a trans-historical quality. In differernt epochs, it manifested itself in different art forms and genres. The current trend can be defined as Post-Neo-Romanticism, as it combines numerous references to the Neo-Romantic paradigm with Postmodernist interpretational techniques. Here Neo-Romanticism appears in a recognizable but hypertrophied form ("hyperromantism"), often with shifted emphasis or transformed genre system. Having a set of characteristics, Post-NeoRromanticism can have a wide range of specific forms depending on the type and genre of art, national tradition, target audience, etc. The development of a classification of its variants deserves a separate study.

Post-Neo-Romanticism tends to mid-cult, and its significant works are semantically multi-layered. For instance, the form of the classical detective can be used to express the contemporary author's view on the history of the major world problems and their current state. For instance, Guy Ritchie's "Sherlock Holmes" dylogy can be seen as a complete historiosophical research in the artistic form. 
Post-Neo-Romanticism as a large-scale mindset emerged spontaneously as a reaction to the ideological and aesthetic demands of a large part of modern society. Numerous works of art, and whole forms and genres tending to this cultural complex are well known in the contemporary Cultural Studies. However, we see them as a complete new cultural phenomenon. Its further study would help to understand: 1) the subtexts of the specific forms, taken in a larger cultural context; 2) the current state and perspectives of the contemporary culture in search of a new "big style" to follow Postmodernism.

\section{SUMMARY}

The article deals with the contemporary culture phenomenon, which is defined as "Post-Neo-Romanticism". It is a wide trend that unites nonnaturalistic and non-modernistic tendencies, which are manifested in different popular genres of literature, cinema and other artistic forms. This trend is actively transcending the art, often determining the self-identification of his adherent, which manifests itself in real-life image and behaviour. One of the important characteristics is the large-scale appropriation of characters, plots and entourage of the classical Neo-Romanticism, which is often interpreted with the use of Postmodern techniques. Another feature is hyperbolization, which sometimes reaches the limit of parody and self-parody. If NeoRomanticism created genre canons, then its contemporary version tends to inter-genre synthesis. In particular, fantasy elements are widely introduced into the mainstream literature. One of the best examples of Post-NeoRomanticism is G. Ritchie's "Sherlock Holmes" dylogy, which illustrates such typical features of this trend as re-working of the classical literary source, double coding, combination of the action-driven plot with the philosophical (especially - historiosophical) subtexts. As Post-NeoRomanticism is a new cultural phenomenon, gaining in strength and continually embracing new spheres of culture, its character and tendencies deserve further study.

\section{REFERENCES}

1. Ratsky, I. (1977) The last Plays of Shakespeare and the Tradition of the Romantic Genres in Literature. Shakespearean Readings 1976. Pp. 104-140. [in Russian].

2. Chesterton, G. K. (2020, January 07). A Defence of Detective Stories. Retrieved from: https//www.chesterton.org/a-defence-of-detective-stories/

3. Gaiman, N. (2005) Neverwhere. London, Great Britain: Headline.

4. Summerscale, K. (2008) The Suspicions of Mr. Whicher, or The Murder at Road Hill House. London, Great Britain: Bloomsbury. 
5. Kluger, D. (2005). The Baskerville Mystery: The History of the Classical Detective. Moscow: Text [in Russian].

6. Buchan, J. (2010) The Three Hostages. The Complete Richard Hannay Stories. London, Great Britain: Wordsworth Classics.

Information about the author: Olena Kolesnyk, Doctor of Cultural Studies, Professor, T. H. Shevchenko National University Chernihiv Colehium, 53, Het'mana Polubotka str., Chernihiv, Ukraine, 14013 ORCID ID: orcid.org/0000-0002-0597-6489 